\title{
CONFRONTOS NA ESTÉTICA BENJAMINIANA: ARTE SIMBÓLICA VERSUS ARTE ALEGÓRICA
}

Tereza de Castro Callado $^{1}$

\section{RESUMO}

Da subdivisão do expediente didascálico-místico da arte figurativa medieval em símbolo e alegoria, procedem as designações do símbolo teosófico dos românticos e seu legado - o fenômeno do Judendstil (Artnouveau) da passagem do século XIX$\mathrm{XX}$, em contraposição à alegoria, conceituada, no século XVII como estética do enigmatismo e, posteriormente, como armadura da modernidade - reconhecida na poesia baudelaireana.

Palavras-chave: Alegoria. Símbolo. Enigma. Jugendstil. Baudelaire.

\section{CLASHES IN BENJAMIN'S AESTHETICS: SYMBOLIC ART VERSUS ALLEGORICAL ART}

\begin{abstract}
From the subdivision of didascalic-mystic expedient of figurative art in medieval allegory and symbol proceed the designations of the theosophical symbol of the romantics and their legacy - the phenomenon of Jugendstil (Artnouveau) the turn of the century $X I X-X X$, in contrast to allegory, conceptualized in the seventeenth century as aesthetics of the enigmatism, and later as armor of modernity recognized in Baudelaire's poetry.
\end{abstract}

Keywords: Allegory. Symbol. Puzzle. Jugendstil, Baudelaire.

Cabe a essa reflexão menos uma análise exaustiva dos expedientes estéticos simbólicos e alegóricos do que enfatizar sua relação visceral com as contingências históricas, fazendo justiça, na ótica de Walter Benjamin à criação de uma filosofia da história. Esse procedimento que regressa à história natural, pensando junto com Benjamin, entra em consonância com a filosofia da arte, para aquilatar os motivos, na história das ideias de que a arte é mentora. Pois pertence a um princípio filosófico - quer aceitem alguns ou não - dilatar o espectro das ideias para uma intercessão interdisciplinar que explica o meio termo entre extremos do pensar filosófico, de que Allegorie e símbolo, na concepção benjaminiana, assumem a polarização, não apenas para explicar o factual, mas principalmente na semiótica da destinação humana. Sabe-se que a transformação de uma mentalidade é inscrita na linguagem

\footnotetext{
1 Tereza de Castro Callado é professora de Filosofia na Universidade Estadual do Ceará.
} 
com seu poder de representar. E renunciar a ela é "renunciar àquele elemento de verdade visado pela linguagem". ${ }^{2}$ Por isso mesmo a representação segue precedida pela crítica. Cabe à filosofia chegar à ideia, através da representação: "a ideia é algo de linguístico, é o elemento simbólico presente na essência da palavra" ${ }^{3}$ Ela deve ascender, de uma forma ou de outra, mesmo em épocas sacudidas pela instabilidade, nesse caso, fomentada a uma posição periférica, exigindo a revolução, meio à pressão de grandes concentrações do pensamento hegemônico. É própria da Allegorie centrar-se no aspecto "sinuoso", digamos assim, na superfície das significações. Mesmo quando não facultada a crítica aos meandros ideológicos associados a totalitarismos, a linguagem imagética ou escritural pode constituir moldura e conteúdo simultaneamente desse espelhamento, mas com um disfarce visando à superação. Ela coleia entre os valores de sentido, emprestando a um e outro o que lhe falta, o que não a isenta da melancolia. É seu aspecto enigmático. Isso acontece à Allegorie. Na ordem e origem que interessam a Benjamin, para um equacionamento das instâncias e prerrogativas da modernidade - e estamos nos referindo ao século XVII, onde o filósofo vê a pré-história da era baudelaireana - ela (a Allegorie) contracena na dramaturgia barroca (Trauerspiel), situada como "um ritmo intermitente de uma pausa constante, de uma súbita mudança de direção e de uma nova rigidez". ${ }^{4}$ Essa intermitência se deve à melancolia diante da pressão e fermentação das ideias. Ao serem desintegrados pela ordem estabelecida, os elementos singulares, sem espaço no conceito, e portanto recolhidos pela Allegorie, oferecem o traçado ininterrupto de um esforço titânico, porque proibidos pela convenção, em busca do sentido do humano que se dispersou. ${ }^{5}$ É assim que a Allegorie assume a desantropomorfização, ou seja denuncia o aspecto falseado do aparecimento de um sujeito lógico, deduzido do Eu cartesiano, proposição retomada por Novalis quando aponta, nos seus estudos sobre poesia, que "o início do Eu é

\footnotetext{
2 Walter Benjamin, Origem do drama barroco alemão, Tradução de Sérgio Paulo Rouanet, São Paulo: Brasiliense, 1984, p. 49.

3 Idem, ibidem, p. 58.

4 Idem, ibidem, p. 221.

5 "Nessa definição o ritmo intermitente não deixa de evoca a crítica à história em uma concepção linear. A pausa constante lembra o ato reflexivo. A súbita mudança de direção investe contra a antiga ordem. E na nova rigidez repercute um outro apelo à estabilidade".Tereza de Castro Callado. "O drama da alegoria no século XVII barroco" in Kalagatos - Revista de Filosofia do Mestrado Acadêmico em Filosofia da Universidade Estadual do Ceará, Fortaleza: Eduece, 2004, p. 135.
} 
meramente ideal". ${ }^{6}$ Ao lado de Schlegel, que defende a tese da fragmentação ${ }^{7}$ como realidade do seu tempo, Benjamin reconceitua a Allegorie como estética do enigmatismo para estampar a sensação de um descentramento e de uma perda, assumida com a dissolução da arte figurativa medieval em que essa expressão atuava ao lado do símbolo teológico, para falar da magia e do encantamento de um mundo contemplado pelo numinoso. No barroco "a imanência da história com a natureza, imanentização que está na base do alegórico, veio ao encontro da própria história da Salvação". ${ }^{8} \mathrm{Na}$ teologia do medievo, da qual o século XVII barroco guarda remanescentes, a morte do cristão pode ser interpretada como vida. Por isso, a Allegorie está desde já "proibida pela culpa de encontrar em si mesma, o sentido", o que dilata o seu sentido de alteridade, que não deixa de buscar, na elaboração formal mais intensa, "infinitamente preparatória, cheia de rodeios, voluptuosamente hesitante". ${ }^{9}$ Nesses revoluteios sem fim, perpetua-se a dialética morte-vida da mística cristã, o que torna, no século XVII as impregnações alegóricas visíveis em níveis distintos de recursos imagéticos, mesmo profanos, que se imantam ao cenário de destruição, tendo na corte barroca seu microcosmo. Esse recurso do sentido precisa se ocultar para permanecer, surge, concomitante ao nascimento das ciências empíricas, ao lado da percepção da falência do conhecimento, instado, pelo poder, a se transformar em posse (Erkenntnis ist ein Haben). ${ }^{10}$ Portanto esse expediente recebe uma nova interpretação a partir da razão instrumentalizada, para poder decifrar seu enigma. Uma vez apropriado na consciência, o saber tecnológico se distancia da verdade, que não tem intenção e se auto-representa no fenômeno da arte, no seu teor de verdade (Wahrheitsgehalt), quando seu conteúdo factual não entra mais em questão. Assim procede a Allegorie no claro-escuro do barroco, no jogo de desvelar-esconder. Sua pertinência está na Arte de saber ocultar: "esconder é deixar rastros. Mas invisíveis". ${ }^{11}$ A Allegorie revela-se na medida em que disfarça seu objeto. Ela guarda essa propriedade da

\footnotetext{
6 Walter Benjamin. Conceito de Crítica de arte no romantismo alemão Tradução, prefácio e notas de Márcio Seligmann-Silva, São Paulo: Iluminuras, 1999, p. 73.

7 Friedrich Schlegel. O Dialeto dos Fragmentos, Tradução, apresentação e notas de Márcio Suzuki, São Paulo lluminuras, 1997.

8 Walter Benjamin. "Perda alegórica da alma" in__ Documentos de Cultura Documentos de Barbárie (Organização e Tradução de Willi Bolle), São Paulo: Cultrix, 1986, p. 35.

9 Walter Benjamin. "Perda alegórica da alma" in_Documentos de Cultura Documentos de Barbárie (Organização e Tradução de Willi Bolle), São Paulo, Cultrix, 1986, p. 35

${ }^{10}$ Walter Benjamin. Origem do drama barroco alemão. Opus cit, p. 51

${ }^{11}$ Walter Benjamin. "A Arte de esconder" in__Documentos de Cultura Documentos de Barbárie, Tradução e notas de Willi Bolle), São Paulo: Cultrix, 1984, p. 188.
} 
verdade (Aletheia): despedir a intencionalidade. A distinção entre o símbolo, inscrito na tradição filosófica da verdade teológica e a alegoria, reconceituada por Walter Benjamin após a leitura de Les Fleurs du Mal de Baudelaire, torna urgente a decisão de uma leitura da história a contrapelo, como recomenda a tese 7 de Über den Begriff der Geschichte,$^{12}$ iniciativa essa que põe à mostra a existência de uma fenda no espaço semântico das diferenças conceituais assumida pela arte alegórica, para descrever a realidade de seu tempo, ao contrário do que acontece às propriedades significativas do símbolo, que no mais das vezes cristaliza a significação. A gênese do contraponto entre símbolo e alegoria tinha sido objeto das reflexões de Walter Benjamin sobre a linguagem fragmentária, no texto de Origem do drama barroco alemão, onde fica patente o distanciamento da Allegorie do expediente linguístico simbólico. Sabe-se que ambas as instâncias significativas que apelam para o jogo imagético formavam, na sua gênese, uma unidade, enquanto recurso didascálicomistico da arte figurativa medieval. Guardiã de uma verdade, essa época não conhecia a necessidade de uma bipartição da metáfora sagrada para conceituar o divino, traduzido igualmente através de símbolos e alegorias, na ilustração dos mistérios. A descoberta dessa origem comum leva Benjamin a compreender, para a profusão de sentidos fornecidos pela Allegorie, o manancial da emblemática dos antigos, equiparando-se o aspecto enigmático da escrita hieroglífica e o poder evocativo das runas (entre os bárbaros) até os sinais desenhados nas paredes das catacumbas onde se reuniam os cristãos. Do trabalho filológico sobre o drama e seu expediente alegórico se pode deduzir o empenho de Walter Benjamin em caracterizar, de forma diferenciada as duas posturas estéticas, uma derivando de um arsenal de recursos instigantes para sobreviver, a outra comodamente instalada na posição privilegiada dos dominadores. Parte da visão dessa dualidade o projeto benjaminiano de uma filosofia da história que possa dar conta das mudanças impactantes dos tempos modernos, frente às desproporções comportamentais, sejam sociais ou político-ideológicas. Tal projeto tem sua fundação no equacionamento da cultura, em seu estágio avançado, enquanto local de barbárie. Essa reflexão abre a hipótese de que Benjamin estaria vendo na linguagem - para além da Phrase, ou seja, na retórica enquanto ferramenta de poder, a possibilidade de desarticular seus mecanismos viciados na informação e na comunicação,

\footnotetext{
${ }^{12}$ Walter Benjamin. Tese 7 de "Sobre o Conceito de História" in___ Magia e Técnica, Arte e Política. Tradução de Sérgio Paulo Rouanet, São Paulo: Brasiliense, 1984, p. 225.
} 
conforme a proposta de uma outra teoria do conhecimento. Uma ótica dessa natureza seria fundante de uma mentalidade que pudesse fazer jus às diferenças, antes camufladas no aparente equilíbrio do classicismo renascentista, o que Benjamin de fato irá realizar em sua crítica gnoseológica à totalidade iluminada pelo símbolo. Se o Símbolo cristaliza o sentido, a Allegorie o multiplica. A physis bela e sensual do classicismo só poderia ser transcrita no espaço simbólico de uma harmonia pré-estabelecida, enquanto a Allegorie se vê liberta de condicionamentos, ou seja, de qualquer preceito doutrinário imperativo, com o fim precípuo de significar, em nome de um teor de alteridade. Já o símbolo vê o sentido cristalizado, reinando ad aeternum em torno da soberania de uma mesma significação. Enquanto a mobilidade pertence à Allegorie, e a faz pairar sobre as intempéries e cataclismos históricos, para desarticulá-los enquanto eventos do poder, o símbolo persiste em uma pseudo-sobrevivência, conceituando indefinidamente o estaqbelecido. "No conceito ao qual obviamente correspondia o símbolo, a palavra que realiza sua essência como ideia se despotencializa", ${ }^{13}$ afirma Benjamin ao analisar os recursos da arte barroca para representar a história em imanência com a natureza, declinando o sentido decadente da physis na concepção de facies hippocratica da história. Com essa revelação fica selada a supremacia da Allegorie na função de denunciar os vícios da corte, enquanto ebulição dos afetos mal direcionados, na criatura. Sabe-se que o alimento principal da estética alegórica "é a corte transformada em cenário". ${ }^{14}$ Sua realidade está totalmente mergulhada nas erupções humanas das paixões, no império absoluto da subjetividade do monarca, na situação de anomia que caracteriza o terreno movediço da transição entre o sistema teocrático do medievo e o estabelecimento definitivo da Razão de Estado. Essa realidade encontra na Allegorie a possibilidade de ser digerida em forma de uma vertigem do sentido, que não dispensa nem o caótico, e por isso mesmo pertence a ela uma dinâmica que deve contornar até o olhar enviesado sobre a realidade ( trompe l'oeil ) e por isso mesmo só pode ser mitigado no instante, com o carpe diem. A Allegorie é sensível à efemeridade das coisas e da existência. Tem a nostalgia de uma permanência. Por isso une o permanente ao transitório, com o sentimento de que o eterno não pertence mais à salvação. Bem observa Lindner,

\footnotetext{
${ }^{13}$ Walter Benjamin. Origem do drama barroco alemão, Tradução de Sérgio Paulo Rouanet, São Paulo: Brasiliense, 1984, p. 64.

${ }^{14}$ Walter Benjamin. Origem do drama barroco alemão, Opus cit, p. 115.
} 
"Na Allegorie, como forma de expressão estética, se realiza - e isto é uma descoberta de Benjamin - a renovação fragmentada e em forma de máscara, da experiência melancólica de uma história do mundo imersa em fixidez mortal". ${ }^{15}$

Ela compreende que "o luto é o estado de espirito em que o sentimento reanima o mundo vazio sob a forma de uma máscara para obter da visão desse mundo uma compensação enigmática". ${ }^{16} \mathrm{O}$ seu desenlace do símbolo teológico cristão se dá ao ser convocada para representar o fim das concepções divinatórias, no processo de perda da magia do mundo (desencantamento do mundo Entzauberung der Welt) sob o domínio da racionalidade científica. É quando assume a melancolia, projetando-se em uma reflexão abissal, para o qual o conceito se vê impossibilitado a qualquer definição. Pois ele ressurge da imediatidade, na comunicabilidade própria à abstração, esquecendo a imediatidade na comunicação do concreto, que o precipita no "abismo da palavra como meio". ${ }^{17}$ Contrariando essa atividade, que tem por fim, exercitar o caráter mediado da palavra, a serviço da Phrase e do ato judicante, de que o mito é o maior mentor, a Allegorie, na sua busca labiríntica pela ideia, percorre, num torvelinho sem fim, as contorções do pensamento até encontrar, nas forças físicas do Grübeln (ruminar), o sentido mais visceral da organicidade conjugada à arte de meditar o objeto até a destruição. Nesse estilhaçamento, a que está destinado o ciclo vital da natureza, ela consegue desarticular a supremacia intelectiva do espirito, considerado por Benjamin como "a faculdade de exercer a ditadura", para devolver ao corporal a sua antiga função, como acontecia à arte clássica da antiguidade grega, em que o espírito apalpava a matéria, antes da hegemonia cristã incontestada do medievo em que a arte se transforma em objeto de culto (Kultwert). Na dialética construção-destruição do método do desvio (Umweg) benjaminiano, a desintegração do objeto contemplado pela Allegorie, retém daquela época a promessa da redenção desse objeto através da dialética vida-morte da teologia cristã. Enquanto uma "figura tardia baseada em

\footnotetext{
${ }^{15}$ In der Allegorie als ästhetischer Ausdrucksform vollzieht sich, und das ist durchaus Benjamins Entdeckung, die maskenhafte, fragmentierende Neubelebung der melancholischen Erfahrung einer in Todesstarre versinkenden Geschichte der Welt. Burkhardt Lindner "Allegorie" in Benjamins Begriffe (Herausgegeben von Michael Opitz und Erdmut Wizisla),, Frankfurt am Main: Suhrkamp Verlag, 2000, p. 51.

${ }_{17}^{16}$ Walter Benjamin. Origem do drama barroco alemão, Opus cit, p. 162,

${ }^{17}$ Walter Benjamin. "Sobre a linguagem em geral e a linguagem dos homens" in: Escritos sobre mito e linguagem. Tradução Susana Kampff Lages e Ernani Chaves, São Paulo: Duas Cidades, 2011, pp. 68-69.
} 
ricos conflitos culturais" a Allegorie tem sua origem no apelo ao inconsciente como local de verdade da criatura. Pois a consciência para Benjamin enfrenta um estágio de embotamento, narcose deletério-onírica que dissolve a verdadeira existência na fantasmagoria da metrópole moderna, incapacitando-a para a decisão política. A estética alegórica absorve as épocas históricas de decadência para articulá-las em uma aporia filosófica, só resolvida pela ideia. Por isso diz Benjamin que a Allegorie é o divertimento do melancólico. É Pascal que nos fala do divertissement: perder-se em devaneios em busca de um sentido para a existência, diante da inutilidade das coisas projetadas pela ciência é o que podemos deduzir da gravura de Albrecht Dürer. Ela ilustra essa fragilidade com a figura alada de uma mulher-anjo cercada de artefatos engendrados pelo conhecimento, para a instrumentalização da ciência, sob o pretexto da operacionalização do saber para fins de humanidade. É fácil deduzir do olhar terrificante da mulher, a evocação igualmente terrível que o domínio daqueles instrumentos poderá representar nos tempos vindouros, sobretudo com a tecnologia da destruição em massa, nas guerras devastadoras do século XX. Não seria uma incoerência dizer que a escolha do quadro para interrogar o destino da ciência do homem teria um eco no tom premonitório de Benjamin no ensaio de 1921 Zur Kritik der Gewalt, quanto aos horrores experimentados pela violência da guerra imperialista sob o aval da técnica. Outra Allegorie cuja riqueza semântica fascinou Benjamin, encontra-se na pintura de um anjo de Paul Klee que ele interpretou como Angelus Novus, destinado a ser um leitor-historiador da saga do poder. $\mathrm{O}$ anjo, encarnando simultaneamente o satanismo do questionador, se insurge contra o estabelecido. Insatisfeito com o desenrolar da história, ele põe em questão a marcha da civilização, é quando se volta para o passado dando as costas ao futuro, para onde é impulsionado por uma tempestade que sopra do paraíso. ${ }^{18}$ Nesse gesto resoluto, o anjo sabe que sua tarefa é despertar os mortos, recolher o que resta da ruína que não cessa de crescer e se acumula elevando-se até o céu. A perplexidade diante dessa constatação não demove o anjo da sua intuição. Ele sabe que alguma

\footnotetext{
${ }^{18}$ Diz Benjamin que o cristianismo do tempo da reforma não favoreceu o aparecimento do capitalismo, mas ele mesmo se transformou no capitalismo: "Das Christentum zur Reformationszeit hat nicht das Aufkommen des Kapitalismus begünstigt, sondern es hat sich in den Kapitalismus umgewandelt." No texto da tese 9 de Sobre o Conceito de História, a noção de paraíso é altamente controversa. Sem deixar de lembrar o paraíso cristão prometido para o homem justo, ele parece derivar daquela tese que compara o catolicismo com o capitalismo, por uma origem comum: a intenção de um lucro projetado para o futuro e de um conhecimento que possa trazer a salvação, persistem em forma de uma promessa. Kapitalismus als Religion in___Gesammelte Schriften, vol VI, Frankfurt am Main: Suhrkamp Verlag, 1999, pp. 102-103.
} 
coisa sobreviveu do sentido, embora somente em forma de fragmento, e sobretudo que esses fragmentos significativos do que restou da tradição precisam ser recolhidos pela sensibilidade agora reintegrada à razão. Benjamin coloca essa nova sensibilidade estética realizada na poesia de Baudelaire como pano de fundo para realçar a falência do espírito crítico de uma época, constatada nas figurações da artnouveu. Ela parece constituir o legado deixado pelo símbolo teosófico dos românticos. Nos traços frágeis da figura feminina e lânguida do Jugendstil (Artnouveau) da passagem do século XIX-XX já se antevê a palidez cadavérica cobrindo os campos de batalha da Guerra imperialista gerida pelos reagentes econômicos em conivência com a força tecnológica. A estratégica romântica de dissolver "a ética no mundo do belo, realizada na estética teosófica dos românticos já tinha sido comprovada fraudulenta desde o classicismo" em que o brilho de uma falsa harmonia, expresso no símbolo, camuflava a verdade histórica. Estes desconheciam a indistinção entre escrita e alegoria e relegavam esta ao plano da imagem conceitual. ${ }^{19}$ Superando o poder conceitual do simbólico para descrição da realidade, a alegoria, ao contrário daquele, consegue transitar entre os extremos uma vez que a ideia assumida por ela contém a verdade de um tempo. Se "a ideia é a configuração em que um extremo se encontra com outro extremo", ${ }^{20}$ a verdade, que constrói a Allegorie de uma época, se mantem como o "equilíbrio tonal dessas essências", ou seja, como uma constelação das ideias, da mesma forma que um conglomerado de estrelas, sem que uma possua uma relação de posse ou derivação de outra. O símbolo ao contrário, como foi desenvolvido pelos estetas românticos "em busca de um saber do absoluto", ${ }^{21}$ se apresenta como signo de ideias [...] sempre igual a si mesmo, já a alegoria "mergulha no abismo que separa o ser visual e sua significação". ${ }^{22}$ Ela não teme esse contratempo, se constitui como armadura da modernidade - reconhecida na poesia baudelaireana e posteriormente na estética expressionista. A Allegorie se imanta ao gênero crítico dos tempos modernos, que surge ao lado da representação para preencher a lacuna deixada pelo desaparecimento das concepções divinatórias - selando a vitória da ciência sobre o mito, do entendimento sobre a magia, da racionalidade sobre os afetos. Atuando ao

\footnotetext{
${ }^{19}$ Tereza de Castro Callado. O drama da alegoria no século XVII barroco in cit, p. 162.

${ }^{20}$ Walter Benjamin. Origem do drama barroco alemão, Opus cit, p. 57.

21 Idem, ibidem. p. 138.

22 Idem, ibidem. p. 144. Kalagatos, Opus
} 
lado do símbolo utilizado pelo Jugendstil, combate seu esoterismo de elevar a arte ao aurático, no cenário do mito moderno de Paris, onde a cativante estereotipia do sentido, resultante do casamento do símbolo com a técnica triunfa sobre a realidade, no abrigo de um mundo ideal de permanência, como acontece em uma neurose infantil, infantilidade essa pensada e sanada com a Allegorie expressionista. A denúncia baudelaireana ao modus vivendi - no cenário dos estereótipos e das fisiologias que habitam a cidade de Paris de Haussmann - analisada por Benjamin naquela poesia, confirma a origem desse expediente estético - que se realiza enquanto expressão da convenção de um tempo - nos artifícios alegóricos do esbanjamento (Verschwendung) de sentido do barroco e sua derivação, na emblemática dos antigos. Prolongando-se no expressionismo alemão, ele tem como patrono o pintor El Grego, diz Benjamin. Se o brilho do símbolo hipnotiza a realidade em nome do poder - e foi o que aconteceu a estética da Belle Époque - , é porque ela possuía condicionamentos míticos, possivelmente úteis para empanar o desmoronamento de valores da era bismarquiana, no caso alemão. É essa a interpretação da lividez alarmante da infertilidade das figuras femininas do Jugendstil e que encontra na alegoria de Baudelaire seu adversário mais forte, na nobreza de rejeitar a opção fácil de camuflar a história do poder. Benjamin observa no jogo do fascínio exalado pelo simbólico, o perigo da sedução vazia e portanto suscetível a impregnações ideológicas. Essa estratégia construída sob o império da intencionalidade, e sobre o cânon da impessoalidade do artista, permitiu, ao eliminar a unidade do singular, a contaminação de preceitos doutrinários imperativos, estabelecidos na política da eugenia ariana do nacional socialismo.

Concluindo queremos enfatizar a riqueza de variantes históricas assimiladas pela Allegorie da arte seiscentista, sob o prisma ambivalente da imanência e da transcendência, como reflexo último da condição do homem projetado no espaço de indefinição da metrópole. Por enquanto o aspecto político da Allegorie joga todas as cartas na ironia - desferida contra a fantasmagoria e o sonho coletivo do mercado estratégia de sobrevivência diante do choque e único referencial. 


\section{REFERÊNCIAS}

AGAMBEN, Giorgio, O que é o contemporâneo? e outros ensaios. Chapecó, SC: Argos, 2009.

BAUDELAIRE, Charles. Obras Estéticas - Filosofia da imaginação criadora. Tradução de Edison Darci Heldt. Petrópolis, RJ: Vozes, 1993.

Nova Fronteira, 1985.

As Flores do Mal. Tradução de Ivan Junqueira. Rio de Janeiro:

BENJAMIN, Walter. Origem do drama barroco alemão, Tradução de Sérgio Paulo Rouanet, São Paulo: Brasiliense, 1984.

1993

Gesammelte Schriften, Frankfurt am Main: Suhrkamp Verlag,

Rouanet, 1985.

Magia e Técnica, Arte e Política. Tradução de Sérgio Paulo

Rua de Mão Única. Tradução de Rubens Rodrigues Torres Filho e José Carlos Martins Barbosa, São Paulo: Brasiliense, 1987.

Charles Baudelaire - um lírico no auge do capitalismo, Tradução de José Carlos Martins Barbosa e Hemerson Alves Baptista, São Paulo: Brasiliense, 1989.

. Illuminationen, Frankfurt am Main: Suhrkamp Verlag, 1977.

CALLADO, Tereza de Castro. "O drama da alegoria no século XVII barroco" in: Kalagatos - Revista do Mestrado Acadêmico em Filosofia, Fortaleza: Eduece, 2004.

DIDI-HUBERMAN, Georges, Sobrevivência dos vaga-lumes, Tradução de Vera Casa Nova e Márcia Arbex, Belo Horizonte: Editora UFMG, 2011. HANSEN, João Adolfo. Alegoria, São Paulo: Atual, 1987.

KLIBANSKY, Raymond, PANOFSKY, Erwin, FRITZ, Saxl. Saturne et la Mélancolie, Paris: Gallimard, 1989.

LINDNER, Burkhardt. "Allegorie" in: Benjamins Begriffe (Herausgegeben von OPITZ, Michael und WIZISLA, Erdmut), Frankfurt am Main: Suhrkamp Verlag, 2000. 